\title{
Burying receivers for improved time-lapse seismic repeatability: CO2CRC Otway field experiment
}

\section{Valeriya Shulakova ${ }^{1,2}$, Roman Pevzner ${ }^{2,3}$, J. Christian Dupuis ${ }^{2,3, *}$, Milovan Urosevic ${ }^{2,3}$, Konstantin Tertyshnikov ${ }^{3}$, David E. Lumley ${ }^{2,4}$ and Boris Gurevich ${ }^{1,2,3}$}

${ }^{1}$ CSIRO Earth Science and Resource Engineering, 26 Dick Perry Avenue, Kensington. WA 6151, Australia

${ }^{2}$ Cooperative Research Centre for Greenhouse Gas Technologies (CO2CRC), Australia

${ }^{3}$ Curtin University, GPO Box U1987, Perth, WA 6845, Australia

${ }^{4}$ The University of Western Australia, 35 Stirling Highway, Crawley, WA 6009 Australia

*Present address: Université Laval, Pavillon Adrien-Pouliot, 1065, av. de la Médecine, Québec G1V0A6, Canada

Corresponding author: Valeriya Shulakova (Valeriya.Shulakova@csiro.au) 


\begin{abstract}
4D seismic is widely used to remotely monitor fluid movement through a reservoir. This technique is especially effective off shore where high survey repeatability can be achieved. It comes as no surprise that the first $4 \mathrm{D}$ seismic that successfully monitored the $\mathrm{CO}_{2}$ sequestration process was recorded off shore in the Sleipner field, North Sea. In the case of land projects, poor repeatability of the land seismic data due to low $\mathrm{S} / \mathrm{N}$ ratio often obscures the time-lapse seismic signal. Hence for a successful on shore monitoring program improving seismic repeatability is essential.
\end{abstract}

Stage 2 of the CO2CRC Otway project involves an injection of a small amount (around 15,000 tonnes) of $\mathrm{CO}_{2} / \mathrm{CH}_{4}$ gas mixture into a saline aquifer at a depth of approximately $1.5 \mathrm{~km}$. Previous studies at this site showed that seismic repeatability is relatively low due to variations in weather conditions, near surface geology and farming activities. In order to improve time-lapse seismic monitoring capabilities a permanent receiver array can be utilised to improve signal to noise ratio and hence repeatability.

A small-scale trial of such an array was conducted at the Otway site in June 2012. A set of 25 geophones was installed in $3 \mathrm{~m}$ deep boreholes in parallel to the same number of surface geophones. In addition, four geophones were placed into boreholes of 1-12 m depth. In order to assess the gain in the signal-to-noise ratio and repeatability, both active and passive seismic surveys were carried out. The surveys were conducted in relatively poor weather conditions, with rain, strong wind and thunderstorms. With such an amplified background noise level we find that the noise level for buried geophones is on average $20 \mathrm{~dB}$ lower compared to the surface geophones.

The level of repeatability (pre-stack NRMS) for borehole geophones is $\sim 20 \%$ for a direct wave, $\sim 30 \%$ for the reflected wave and $\sim 50-60 \%$ for ground roll while the same measurements for the 
surface geophones are estimated as $45 \%, 70 \%$ and $100 \%$ respectively. Both borehole and surface geophones produce the best repeatability in the $30-90 \mathrm{~Hz}$ frequency range. The influence of burying depth on $\mathrm{S} / \mathrm{N}$ ratio and repeatability shows that significant improvement in repeatability can be reached at a depth of $3 \mathrm{~m}$. The level of repeatability remains similar between 3 and $12 \mathrm{~m}$ depths. 


\section{Keywords}

Time-lapse seismic; repeatability; buried sensors; passive data registration. 


\section{Introduction}

Time-lapse seismic is now a well-established remote monitoring technique with a wide area of application, ranging from reservoir oil/gas depletion to enhanced oil recovery projects. It is successfully used all over the world in optimising well placement, reservoir characterisation, reducing uncertainty in reservoir development and production decisions (Amundsen and Landro, 2007). It is often an essential part of a monitoring and verification program in $\mathrm{CO}_{2}$ geosequestration projects.

The success of the method strongly depends on the impedance contrast before and after injection, signal-to-noise ratio (SNR), and overall repeatability of the data acquisition and processing stages. 4D seismic was previously mostly applied in marine environments, benefiting from intrinsically high signal to noise ratio. However, recent advances in technology bring time-lapse seismic onshore.

The repeatability of a land seismic survey is affected by the ambient noise (weather conditions, machinery), variation of the source generated noise pattern, velocity variations in the shallow subsurface, source-receiver positioning, variations in acquisition parameters, geophone coupling, and other factors. (Bakulin et al, 2012). All these factors may cause the time-lapse seismic signal to be below the detectable level.

An effective solution addressing the majority of these factors is a permanent installation of buried receivers. The buried geophones effectively suppress ambient surface noise and may be able to reduce the detectability threshold to $1-2 \%$ of impedance change or less by increasing signal energy and enhancing repeatability (Lumley, 2001). The buried receivers were shown to improve wavelet amplitude stability up to 10 times (Berron et al, 2012). Permanent installation also resolves the positioning issues, and provides the possibility to acquire data more frequently (Landro and 
Skopintseva, 2008). Despite all these advantages, permanently buried geophones are not used frequently in practice. The main reasons are the high cost of installation and lack of data substantiating its benefits quantitatively.

The first implementation of a permanent geophone array was on-shore, in the Duri field in Indonesia. The buried geophones were reported to provide a better SNR, though the installation was not fully permanent. The receivers had to be flashed after acquisition as their response deteriorated in mud conditions (Jenkins et al, 1997). The world's largest permanent geophone array buried at 1 $\mathrm{m}$ depth below the sea floor was installed and is now successfully used off-shore in Norway (Gestel et al, 2008).

Using permanent buried installations could be particularly beneficial on-shore, where the presence of complex overburden, rapid variations in source generated noise, seasonal variations and highly variable ambient noise are commonplace.

In order to evaluate various acquisition geometry configurations for on-shore monitoring, such as the depth of the buried array or the type of receiver, a comprehensive on-shore field experiment was conducted in Saudi Arabia (Bakulin et al, 2012). The study demonstrates the importance of the depth of buried receivers in the presence of the complex near-surface. Burying receivers below karsted overburden (down to $30 \mathrm{~m}$ ) provided improvements in signal strength and repeatability of the data (Arts et al, 2011; Bakulin et al, 2012).

Dual surface and subsurface acquisition was applied on-shore at the Ketzin site (CO2SINC Project), Germany. Geophones deployed at $50 \mathrm{~m}$ depth were reported to give superior SNR with respect to the surface geophones. The main advantage was a significant increase in the frequency content of the recorded data (Arts et al, 2011). One step further in increasing the repeatability of the data is to 
bury both receivers and sources (Meunier et al, 2001; Bakulin et al, 2012; Forgues and Schissele, 2010; Bianchi et al, 2004).

Combining active and passive seismic data acquisition may provide additional benefits: continuous monitoring of background noise gives the possibility of using the observed changes in noise level directly to enhance the 4D signal (Landro and Skopintseva, 2008). An automated workflow designed to detect noise events was tested in Ketzin (Santonico et al, 2012). Nørmark (Nørmark, 2011) suggested a noise suppression method based on the study of seismic noise induced by wind and rain and their influence on the data acquired with a land streamer and planted geophones. The present study was conducted to investigate and quality the benefits of permanently installed buried geophones for active seismic monitoring of small-scale $\mathrm{CO}_{2}$ injection as part of the $\mathrm{CO} 2 \mathrm{CRC}$ Otway project, Australia's first geo-sequestration on-shore demonstration project. The first stage of the project was completed in 2010 with 66000 tonnes of $\mathrm{CO}_{2} / \mathrm{CH}_{4}(80 \% / 20 \%)$ gas mix being injected in the depleted gas reservoir at a depth of $\sim 2 \mathrm{~km}$. The plan for the next stage of the project is a gas mix injection into a saline aquifer (the Paaratte formation) at a depth of $\sim 1.5 \mathrm{~km}$. The monitoring program will be focused on testing the effectiveness of time-lapse seismic methodology for the detection of a plume created by injection of small quantities of the gas mixture.

The time-lapse signal at the Otway site caused by this small-scale injection is predicted to be relatively weak due to the small extent and thickness of the plume. Previous studies conducted during the first stage show that one of the key limiting factors for $\mathrm{CO}_{2}$ monitoring can be related to a high ambient noise level (Pevzner et al., 2011). This means that burying geophones underground could be a solution to this problem. To test this assumption we conducted a comprehensive field test in June 2012. In this paper we discuss issues related to the data acquisition and analysis using both buried and surface geophones at the Otway site. 


\section{Permanent receiver array design and data acquisition}

The trial installation of the permanent receiver array was composed of 25 pairs of buried geophones in marsh cases and standard surface geophones. All of the geophones were wired to the same Seistronix EX-6 recorder. The boreholes were drilled to the depth of $3 \mathrm{~m}$ with the use of an auger drill rig. The surface positions (denoted ad SP 1-25) were spaced $10 \mathrm{~m}$ apart along the straight EastWest line at the edge of the CO2CRC Otway site (the receiver line is marked with an orange line in Figure 1). These shallow boreholes were completed using PVC casing with an inner diameter of 70 $\mathrm{mm}$. Granular sodium bentonite was used to seal the last $1 \mathrm{~m}$ of the annulus against surface runoffs. The geophones were placed on the end of a planting pole and lowered down each hole. After fixing the geophone in place the PVC casing was cut and cupped to prevent accidental contamination of the bores. 25 standard geophones were also hand-planted on the surface parallel to the line of $3 \mathrm{~m}$ bores (Figure 2).

Four additional shallow boreholes were drilled in a cluster at the surface position SP 6 (marked with a red dot, Figure 1) and four additional receivers were buried at depths of 1, 6, 9 and $12 \mathrm{~m}$ respectively.

The permanent receiver installation was used for the active and passive data recording.

The field spread for an active experiment was composed of a shot line placed perpendicular to the receiver line and oriented along Soda Road in a South-North direction (marked as blue line in Figure 1). The line was first shot in South-North direction and then back in North-South direction. 150 shots placed $10 \mathrm{~m}$ apart were acquired with a $720 \mathrm{~kg}$ weight drop source mounted on a bobcat. All geophones were live for all 300 shots for both passes, and recorded three seconds of data at one millisecond sample rate. Data acquisition took approximately 4 hours and was completed on June $21,2012$. 
The ambient noise data has been also passively recorded with the same receiver spread as in the active experiment. All of the geophones were recording data almost continuously at $1 \mathrm{~ms}$ sample rate for $\sim 22$ hours starting at 15:26, June 21 and finishing at 13:15, June 22. The data was stored using 60 s length individual traces. The total time of recorded data is 17.5 hours, a few hours of record was lost due to several equipment power failures.

\section{Data Analysis}

The initial processing of the data acquired during the active part of the experiment includes a manual trace editing and DC component removal. An example of seismograms after such preprocessing recorded with borehole and surface geophones at the same surface positions (SP 1-3) is shown in (Figure 3). One can see a significant increase in signal-to-noise ratio due to the burying of the sensor.

\section{Static shifts}

The initial data analysis reveals variable time shifts between two passes recorded at the same shot point with the same geophone.

To calculate these time shifts, we use cross-correlation between corresponding traces from two passes within a $600 \mathrm{~ms}$ window. We apply a correlation coefficient threshold of 0.6 so that all traces that display lower correlation are excluded from the analysis. The distribution of time shifts varies from -3 to $3 \mathrm{~ms}$ (Figure 4). Each dot on the distribution map represents a time shift value for each geophone. The $\mathrm{X}$ and $\mathrm{Y}$ coordinates of the dots correspond to the source and receiver stations, respectively.

We can observe that the apparent distribution of time shifts is broader for surface then for borehole geophones, especially for the sources 125-150 (the northern part of the source line). This is probably caused by greater sensitivity of the surface geophones to the ambient noise which was, in 
turn, affecting the stability of the shift estimates. Borehole and surface geophones at the same surface position should have the same time shifts caused by the source positioning and triggering. Thus the static shifts should be applied to sources rather than to receivers. Figure 5 shows the plot of average static shifts between corresponding sources.

\section{Spectral analysis}

An example of the amplitude spectra calculated for several surface positions for both borehole and surface receivers is plotted on a $\mathrm{dB}$ scale (Figure 6). In general all plots show the same level of signal for the frequency range $\sim 0-50 \mathrm{~Hz}$. The difference between plots for the higher frequencies goes up to $30 \mathrm{~dB}$.

\section{Repeatability}

To evaluate repeatability of borehole and surface geophones we compute the normalized-rootmean-square (NRMS) difference in a sliding window $60 \mathrm{~ms}$ for each pair of corresponding traces at the same surface location acquired at pass 1 and pass 2, using the following equation (Kragh and Christie, 2002):

$$
N R M S=\frac{200 \times R M S\left(a_{i}-b_{i}\right)}{R M S\left(a_{i}\right)+R M S\left(b_{i}\right)},
$$

where $a$ and $b$ represent two passes of the data recording.

Average NRMS values are then estimated in three gates around direct, reflected and surface waves

(Figure 8). An example of NMRS parameter values for borehole and surface geophones from the same locations (SP 1-4, 8-10) is shown in Figure 8. The borehole geophones display a better repeatability as compared to the surface ones. The repeatability also decays more rapidly with time for the surface geophones, especially at times $>1 \mathrm{~s}$.

The next step of the repeatability analysis includes NRMS estimation for different frequency ranges: $10-30 \mathrm{~Hz}, 30-90 \mathrm{~Hz}$ and $90-150 \mathrm{~Hz}$. 
For this purpose the data acquired with borehole and surface geophones are filtered with corresponding zero-phase Ormsby bandpass filters with the following cut-off frequencies: 10-30 $\mathrm{Hz}, 30-90 \mathrm{~Hz}$ and $90-150 \mathrm{~Hz}$. This produces six filtered datasets - three for each type of geophone. Then, NRMS values are calculated, followed by estimation of average NRMS parameters in the gates around direct, reflected and surface waves. The first range of $10-30 \mathrm{~Hz}$ filters out high frequency noise leaving direct wave and ground roll. They are still present in the second range of $30-90 \mathrm{~Hz}$ and are almost filtered out in the third $90-150 \mathrm{~Hz}$ range. Figure 9 shows an example of calculated NRMS values in three different frequency ranges acquired at SP 1-4, 8-10 with borehole and surface geophones respectively. For the first two frequency ranges NRMS values remain almost constant along the direct wave arrival and are $\sim 20 \%$ to $\sim 40 \%$ for borehole and surface geophones respectively. The repeatability decreases for the highest frequency range $90-150 \mathrm{~Hz}$ : 42\% and 67\% for borehole and surface geophones respectively. The repeatability of the ground roll decreases gradually for both geophone types: $57 \%, 94 \%$ and $131 \%$ for all frequency ranges for borehole geophone and $80 \%, 113 \%$ and $137 \%$ for surface geophone.

\section{Noise pattern analysis}

In addition to analysing the SNR for active sources, we have attempted to characterise site-specific noise pattern by having both surface and borehole geophones recording continuously for almost 24 hours. The idea is to identify the principal noise sources and evaluate their effect on both surface and buried geophones. Typical spectrograms of the data recorded with borehole and surface geophones at one position SP22 are shown in Figures 10 and 11.

The recorded data for both geophones includes a number of mono-frequency signals contaminated with wide-band ambient noise. As can be clearly seen, the level of this ambient noise is significantly higher for the surface geophones. The analysis of the background noise on both sections reveals the presence of low and high frequency events of various origins. 
Two zones with high noise levels at times 15:00-18:00, June 21 and 8:00-13:00 the next day are associated with seismic crew activity on the site (marked with green brackets in Figure 11).

Three noisy events, marked with blue arrows, at around 17.00-18.00, 23.00, June 21 and at 03.00 on the morning 22 June might be associated with heavy rain which took place on the site. Note the correlation with meteorological data (Table 1).

A number of events with peak frequency at 6-13 Hz are present in the data (ex. around 19:30, 20:30 and 21:30, June 21). They might be associated with heavy vehicles or machinery. The zone from 18.00 , June 21 till 8.00 , June 22 is relatively calm.

A set of strong and weak mono-frequency signals associated with electricity or machinery and its harmonics and some combined frequencies are present for the whole time range (Figure 11 and Table 2).

Additional mono-frequency events are present in the data, e.g. 25, 50, 75 and $100 \mathrm{~Hz}$ for the time range $16.50-17.35$, June 21 and $10.30-13.00$, June, 22. They might be associated with $50 \mathrm{~Hz}$ electrical noise and its harmonics. There is also one extremely narrow-band event with varying frequency from $85 \mathrm{~Hz}$ up to $200 \mathrm{~Hz}$ present throughout the data.

\section{Analysis of the results}

A comprehensive seismic trial experiment including both active and passive data recording was conducted on-shore at the Otway site in Victoria, Australia.

The site specific limitations such as restricted area access, strong variation in source generated noise and a relatively weak 4D signal forced us to search for advanced methods of data acquisition. The 
experiment reveals a number of advantages for the permanent geophone array. The use of buried receivers is clearly beneficial as it is less sensitive to surface noise, eliminates positioning errors, provides a better SNR and repeatability and, once installed, allows less invasive site access.

Figure 12 displays the maps of average absolute amplitude distribution in $\mathrm{dB}$ for the data passively recorded with surface and borehole geophones. These amplitudes can be interpreted as background noise estimates, however one need to keep in mind that surface and borehole geophones can have also different sensitivity (due to both differences in construction of the actual device and differences in coupling conditions). The noise is higher for the surface geophones and its distribution is more uneven. A histogram of the background noise level difference for the surface and buried geophones has the average value of 20-30 dB (Figure 13). In order to check if this is caused by the difference of the actual noise level or sensitivity of the geophones we investigated amplitude of the ground roll as observed on the active shot records. We found that amplitude of the ground roll for most of the buried/surface geophone pairs is $5-50 \%$ higher on the surface geophone. As such, even though, sensitivity of the buried geophones appears to be slightly lower, the biggest contribution to the difference in the observed noise levels is coming from the decrease in the actual noise level. This may indicate the potential magnitude of the noise floor decrease due to the burying of the sensors.

The permanent borehole geophone array also demonstrates better repeatability of the recorded data during the active experiments. In general, the average repeatability is twice as high for the borehole geophones as for the surface ones (Figure 14) for main seismic events - direct, reflected and surface waves. The best repeatability can be observed for the direct wave for both geophones: NRMS is $20 \%$ and $53 \%$, respectively. It deteriorates slightly for the reflected wave to NRMS $42 \%$ and $73 \%$, respectively. The ground roll is less repeatable: the NRMS is $64 \%$ and $101 \%$ respectively. Moreover, the ground roll is non-repeatable even during one season. The result of the subtraction of two seismograms recorded by one borehole receiver is shown in Figure 15. A significant amount of remaining ground roll energy can be seen in the difference seismogram - a cone area in the centre of 
the difference section. We speculate that due to the inevitable change in the source coupling conditions that occur when we repeat the survey, the amount of energy transforming into ground roll will change.

Thus seasonal variations in near surface conditions are not necessary for unrepeatable ground roll, yet such changes can further degrade repeatability.

The repeatability analysis in the different frequency ranges reveals that both surface and buried geophones produce the best repeatability for the direct and reflected waves at 30-90 Hz. Figure 16 combines average NRMS values for borehole (left) and surface (right) geophones for different frequency ranges estimated around direct (shown in blue), reflected (green) and surface (purple) waves in one plot. It then decreases at frequencies $90-150 \mathrm{~Hz}$ as these events are not present at such high frequencies. The repeatability of ground roll gradually decreases with increasing frequency. To answer the question of how the geophone placement affects the repeatability of the data we recorded the signal from 5 different geophones placed at depths of 1, 3, 6, 9 and $12 \mathrm{~m}$ at one surface position SP6 (marked with the red dot near the receiver line in Figure 1). The geophone at $3 \mathrm{~m}$ depth failed, so we included the data from the nearest borehole geophone to complement the analysis.

The plot of the amplitude (dB) spectra calculated for all geophones for both passes (Figure 17) reveals the presence of high frequency noise in the surface geophone data (shown in blue). The noise level recorded at the surface geophone is slightly higher for the second pass. In general, the amplitude spectra for the buried geophones show the same behaviour for both passes.

NRMS values calculated for the corresponding traces from two passes are shown in Figure 18. The colour scale is limited to the range $0-100$. 
The surface and $1 \mathrm{~m}$ depth geophones display almost the same repeatability for the direct wave. We observe a slight increase in repeatability for the ground roll because even $1 \mathrm{~m}$ is enough to suppress surface noise. The optimal receiver burying depth for the Otway site environment is $3 \mathrm{~m}$ as we do not observe further repeatability improvements with increasing depth. The NRMS (\%) value for the direct wave at a depth of $3 \mathrm{~m}$ is approximately $20 \%$, for the reflected wave it is $38 \%$, and for the ground roll it is $58 \%$.

\section{Conclusions}

The field survey was carried out to evaluate performance of buried and surface geophone arrays at the CO2CRC Otway site (Victoria, Australia). This test comprised the active component, in which we acquired one cross-spread survey twice to evaluate the repeatability, and the passive component targeted to site-specific noise characterisation. We summarise here the key findings obtained after the data analysis.

The level of repeatability (pre-stack NRMS) for the borehole geophones is almost twice that of the surface geophones. It is interesting that the level of repeatability for the direct wave is almost twice that of the ground roll, e.g. the ground roll pattern is very sensitive to variation in source conditions (even for the same-day repeat acquisition).

The level of repeatability (pre-stack NRMS) for borehole geophones is $\sim 20 \%$ for a direct wave, $\sim 30 \%$ for the reflected wave and $\sim 50-60 \%$ for ground roll while the same measurements for the surface geophones are estimated as 45\%,70\% and 100\% respectively. Both borehole and surface geophones produce the best repeatability in the $30-90 \mathrm{~Hz}$ frequency range.

The influence of burying depth on $\mathrm{S} / \mathrm{N}$ ratio and repeatability was investigated using geophones located at depths of 1, 3, 6 and $12 \mathrm{~m}$. The repeatability level for the geophone buried $1 \mathrm{~m}$ deep is comparable to that for the surface geophone. Burying receivers at a depth of $3 \mathrm{~m}$ provided 
significant improvement in repeatability. The level of repeatability remains similar between 3 and $12 \mathrm{~m}$ depths.

During the passive component of the experiment all the geophones were almost continuously recording data for $\sim 22$ hours. The data acquired was analysed to identify major noise sources and their impact on both buried and surface geophones. Not surprisingly buried geophones are much less affected by such noise sources as wind and rain with the overall ambient noise level attenuation of 20-30 dB. Spectral analysis of the records reveals the presence of various mono-frequency electrical noises and signals coming from working machinery and other on-site activities.

\section{Acknowledgments}

We acknowledge the contribution of Rajindar Singh, Josie McInerney, Peter Dumesny, Greg Willox, Anton Kepic and Barry Freifeld to the implementation of the experiment.

This work was sponsored in part by Australian Commonwealth Government through Cooperative Research Centre for Greenhouse Gas Technologies (CO2CRC). The authors wish to acknowledge financial assistance provided through Australian National Low Emissions Coal Research and Development (ANLEC R\&D). ANLEC R\&D is supported by Australian Coal Association Low Emissions Technology Limited and the Australian Government through the Clean Energy Initiative.

\section{References}

Amundsen L. and Landro M. 2007. 4D seismic - status and future challenges. GEO ExPro 66-68.

Arts R., Meekes R., Brouwer J., van der Werf M., Noorlandt R., Paap B., Visser W., Vandeweijer V., Luth S., Giese S. and Maas J. 2011. Results of a monitoring pilot with a permanent buried multi-component seismic array at Ketzin. Energy Procedia 4, 3588-3595. 
Bakulin A., Burnstad R., Jervis M. and Kelamis P. 2012. The feasibility of permanent land seismic monitoring with buried geophones and hydrophones. $79^{\text {th }}$ EAGE conference, Copenhagen, Denmark, Expanded Abstarcts.

Berron C., Forgues E., Jervis M., Bakulin A. and Burnstad R. 2012. Buried sources and receivers in a Karsted Desert environment. $79^{\text {th }}$ EAGE conference, Copenhagen, Denmark, Expanded Abstarcts. Bianchi T., Forgues E., Meunier J., Huguet F. and Bruneau J. 2004. Acquisition and processing challenges in continuous active reservoir monitoring. SEG $74^{\text {th }}$ Annual Meeting, Denver, Colorado, expanded Abstacts.

Forgues E. and Schissele E. 2010. Benefits of hydrophones for land seismic monitoring. $77^{\text {th }} E A G E$ conference, Barcelona, Spain, Expanded Abstarcts.

Gestel J., Kommedal J., Barkved O., Mundal I., Bakke R. and Best K. 2008. Continuous seismic surveillance of Valhall Field. The Leading Edge, 1616-1621.

Jenkins S., Waite M. and Bee M. 1997. Time-lapse monitoring of the Duri steamflood: A pilot and case study.

Kragh E. and Christie P. 2002. Seismic repeatability, normalized rms and predictability. The Leading Edge 21, 640-647.

Landro M. and Skopintseva L. 2008. Potential improvements in reservoir monitoring using permanent seismic receiver arrays. The Leading Edge 27, 1638-1645.

Lumley D. 2001. The next wave in reservoir monitoring; the instrumental oil field. The Leading Edge, 640-648.

Meunier J., Huguet F. and Meynier P. 2001. Reservoir monitoring using permanent sources and vertical receiver antennae: The Cere-la-Ronde case study. The Leading Edge, 622-629.

Nørmark E. 2011. Wind and rain induced noise on reflection seismic data. Near surface $2011-17^{\text {th }}$ Europian meeting of environmental and engineering geophysics, P48.

Pevzner R., Shulakova V., Kepic A. and Urosevic M. 2011. Repeatability analysis of land timelapse seismic data: CO2CRC Otway pilot project case study. Geophysical Prospecting 59, 66-77. 
Pevzner R., Urosevic M., Caspari E., Galvin R., Madadi M., Dance T., Shulakova V., Gurevich B., Tcheverda V. And Cinar Y. 2013. Feasibility study of time-lapse seismic methodology for monitoring the injection of small quantities of $\mathrm{CO}_{2}$ into a saline formation, $\mathrm{CO} 2 \mathrm{CRC}$ Otway project. Energy Procedia 37, 4336-4343.

Santonico D., Zhang X. Verdel A., Meekes J. and Arts R. 2012. The first results of continuous passive surface seismic monitoring at the $\mathrm{CO}_{2}$ injection site of Ketzin. $79^{\text {th }}$ EAGE conference, Copenhagen, Denmark, Expanded Abstarcts.

\section{List of Tables}

Table 1. Warrnambool meteorology data for June 21, 22 from National Climate Centre.

Table 2. The list of different seismic events recorded on a spectrogram from SP22.

\section{List of Figures}

Figure 1. Position of the trial permanent installation.

Figure 2. Borehole construction details and surface location.

Figure 3. An example of raw common receiver point (CRP) seismograms acquired at SP 1-3 with borehole (left) and surface (right) geophones.

Figure 4. The distribution map of static shifts between corresponding traces applied in each geophone.

Figure 5. The plot of static shifts between corresponding sources.

Figure 6. Comparison of the amplitude (dB) spectra for borehole and surface geophones at several surface positions at pass 1 .

Figure 7. NRMS analysis: the gates for an average NRMS values calculations around direct (green), reflected (blue) and surface (pink) waves.

Figure 8. Comparison of NRMS values for borehole (A) and surface (B) geophones. 
Figure 9. An example of NRMS values for borehole geophone data in three frequency ranges: 10-30 $\mathrm{Hz}$ (top), 30-90 Hz (middle) and 90-150 Hz (bottom). G1 and G2 values display NRMS estimations along direct wave arrival and ground roll respectively.

Figure 10. A spectrogram of the raw data acquired at SP 22 with surface (left) and borehole (right) geophones (horizontal axis is the acquisition time (in hours), vertical - frequency).

Figure 11. A fragment of the spectrogram of the raw data acquired at SP 22 with borehole geophones.

Figure 12. Average absolute amplitude on different geophones (in dB scale).

Figure 13. A histogram of noise attenuation.

Figure 14. Average NRMS values for borehole (shown in blue) and surface (shown in purple) geophones for different seismic events: direct wave (top), reflected wave (middle) and ground roll (bottom).

Figure 15. Two corresponding CRP seismograms (a-b) acquired during two different passes at SP 10 and the result of their subtraction (c).

Figure 16. Average NRMS values (\%) for borehole and surface geophones for different frequency ranges estimated around direct, reflected and surface waves.

Figure 17. Comparison of the amplitude $(\mathrm{dB})$ spectra of the raw data at SP 6 for the first pass: one surface geophone and four geophones buried at depths of 1, 6, 9 and $12 \mathrm{~m}$.

Figure 18. NRMS values of the raw data at SP 6 for two passes: one surface geophone and four geophones buried at depths of 1, 6,9 and $12 \mathrm{~m}$. Numbers at the bottom of each figure show average NRMS values in the gates. DW - around direct wave, RW - reflected wave and GR - around surface wave. 
Table 1. Warrnambool meteorology data for June 21, 22 from National Climate Centre.

\begin{tabular}{|c|c|c|c|c|c|c|}
\hline \multirow{2}{*}{ Date } & \multicolumn{2}{|c|}{ Temperature, } & \multirow{3}{*}{ Max Wind Gusts } \\
\cline { 2 - 3 } \cline { 5 - 6 } & \multirow{2}{*}{ Min, ${ }^{\circ} \mathbf{C}$} & Max ${ }^{\circ} \mathbf{C}$ & \multirow{2}{*}{ Rain } & Direction & $\begin{array}{c}\text { Speed, } \\
\mathbf{k m} / \mathbf{h}\end{array}$ & Time \\
\hline June, 21 & 7.5 & 10.7 & 3.4 & SSE & 39 & 20.21 \\
\hline June, 22 & 7.4 & 11.6 & 29.2 & SSE & 57 & 6.00 \\
\hline
\end{tabular}

Table 2. The list of different seismic events recorded on a spectrogram from SP22.

\begin{tabular}{|c|c|c|c|c|}
\hline \multirow{2}{*}{$\begin{array}{c}\text { Frequenc } \\
\mathbf{y}, \mathbf{H z}\end{array}$} & \multirow{2}{*}{ Appearance } & \multicolumn{2}{|c|}{ Presence in the data } & \multirow{2}{*}{ Comments } \\
\cline { 3 - 5 } & $\begin{array}{c}\text { Surface } \\
\text { Geophone }\end{array}$ & $\begin{array}{c}\text { Buried } \\
\text { Geophone }\end{array}$ & - \\
\hline 14.5 & strong & + & + & - \\
\hline 22 & weak & + & + & multiple of $14.5 \mathrm{~Hz}$ \\
\hline 28.5 & weak & + & + & - \\
\hline 29 & weak & + & + & - \\
\hline 39.5 & strong & + & + & combined frequency $29+14.5 \mathrm{~Hz}$ \\
\hline 42.5 & weak & - & + & dotted line appearance \\
\hline 43.5 & weak & + & + & combined frequency $39.5+14.5 \mathrm{~Hz}$ \\
\hline 50 & weak & - & + & combined frequency $50+14.5 \mathrm{~Hz}$ \\
\hline 54.5 & weak & - & + & multiple of $39.5 \mathrm{~Hz}$ \\
\hline 64.6 & weak & - & + & + \\
\hline 79 & weak & + & &
\end{tabular}

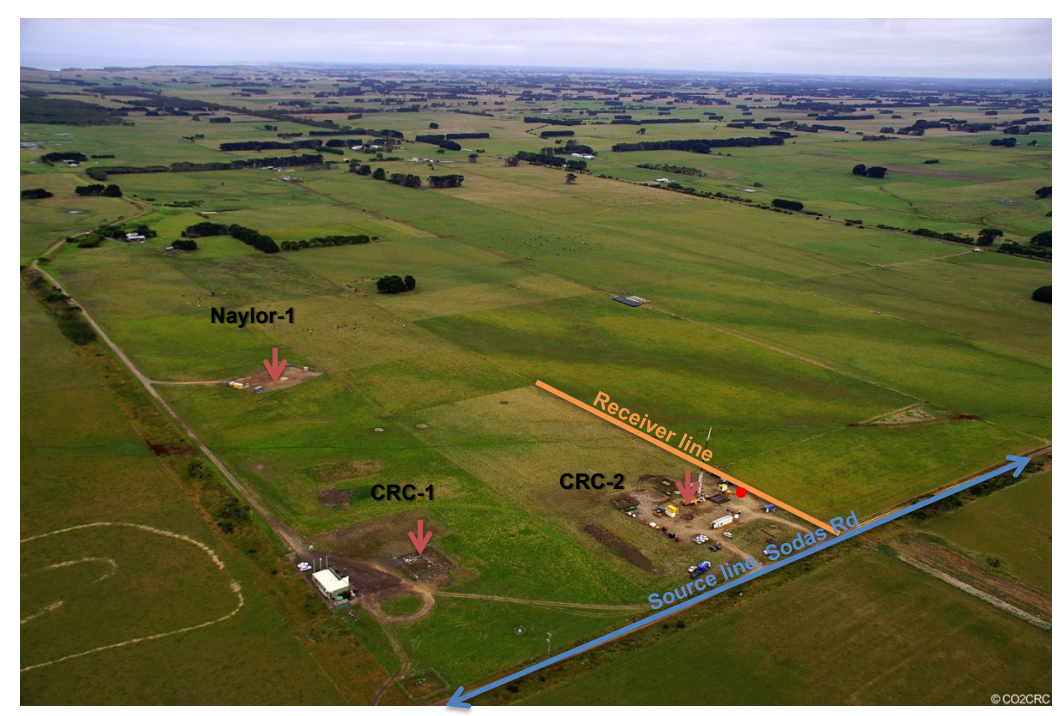

Figure 1. Position of the trial permanent installation. 


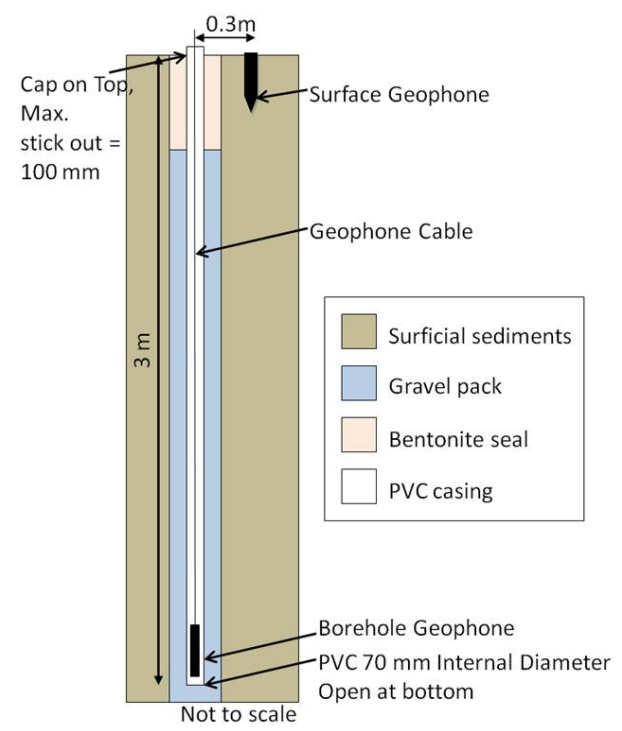

Figure 2. Borehole construction details and surface location.

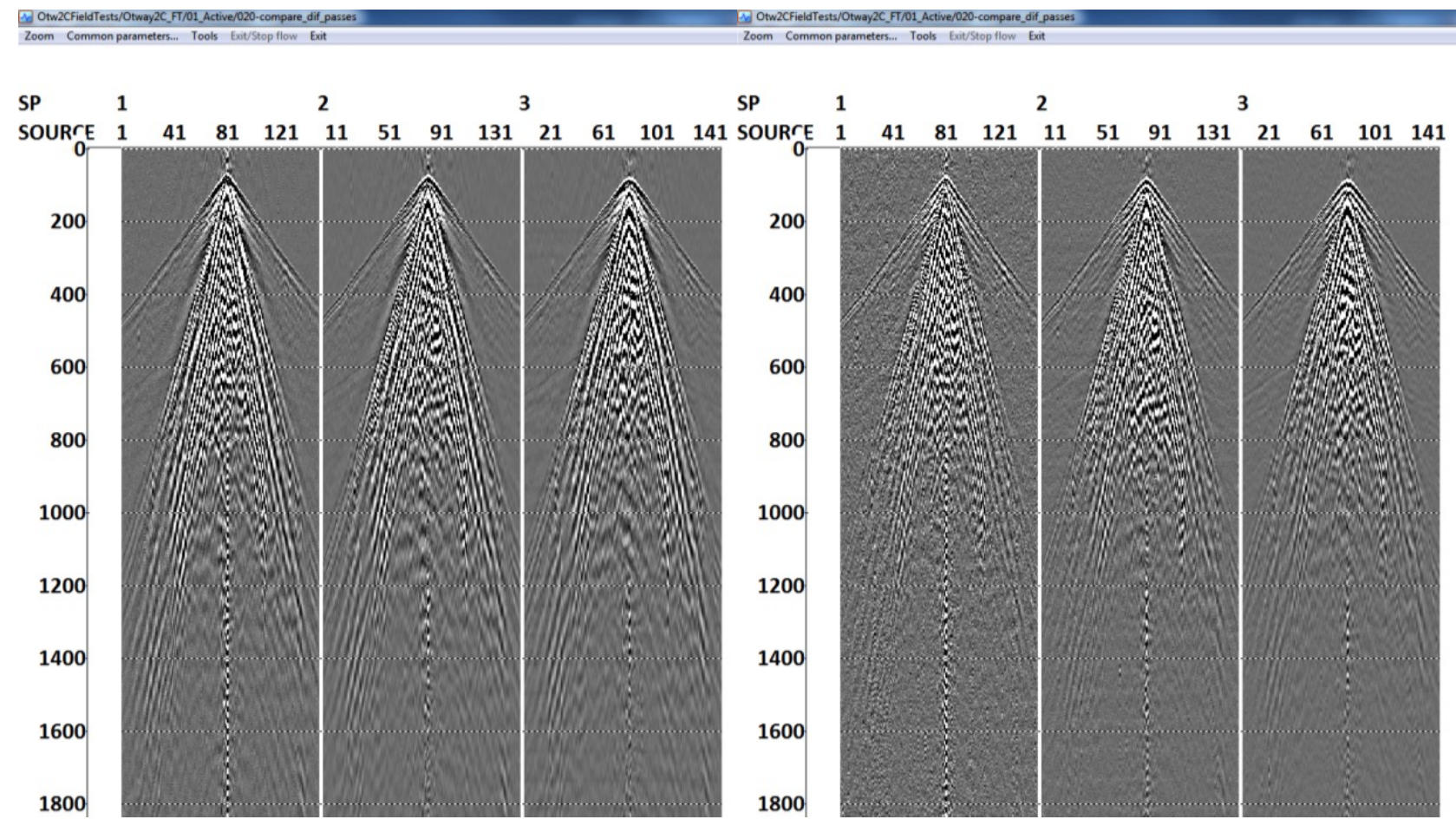

Figure 3. An example of raw common receiver point (CRP) seismograms acquired at SP 1-3 with borehole (left) and surface (right) geophones. 

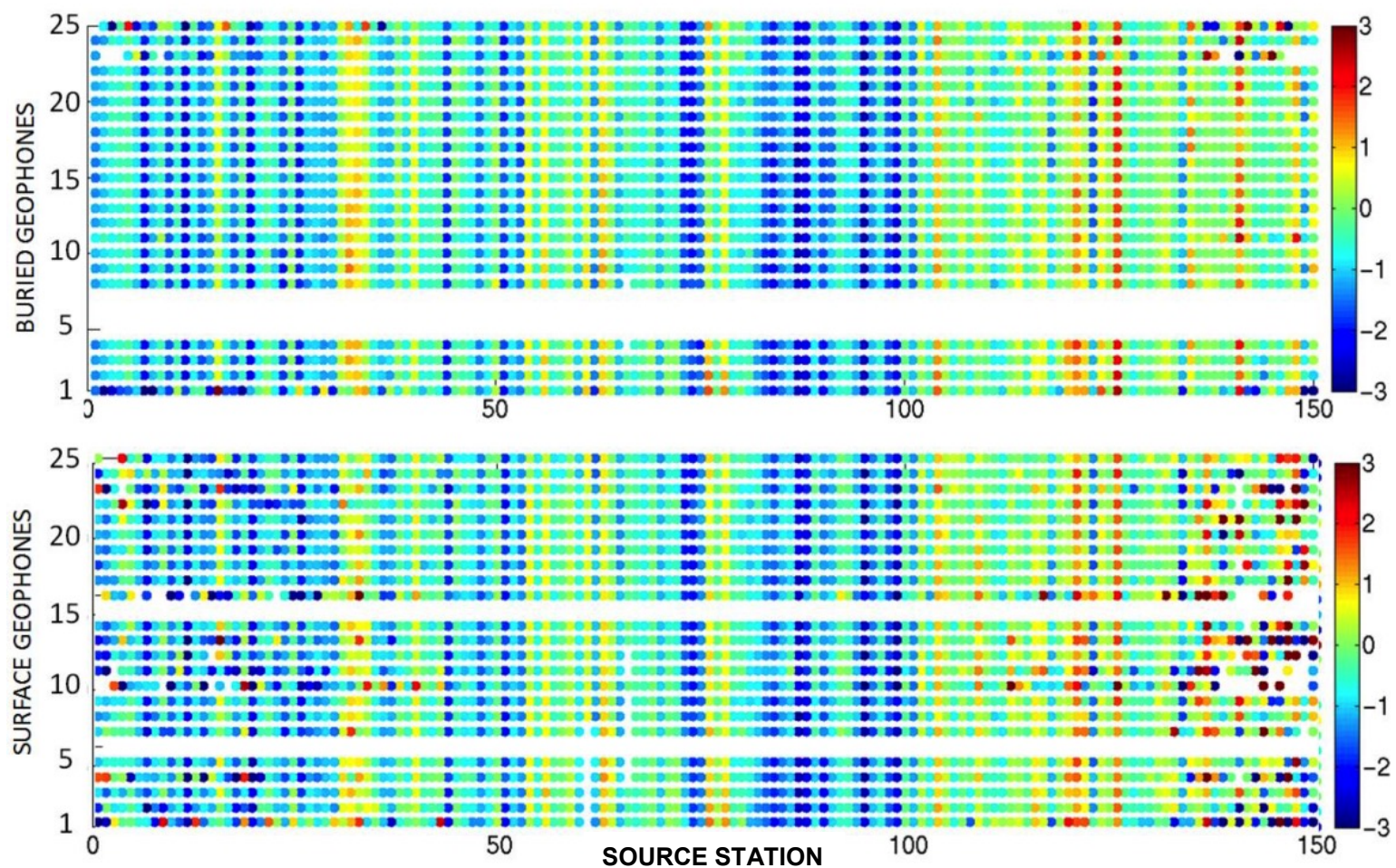

Figure 4. The distribution map of static shifts between corresponding traces applied in each geophone.

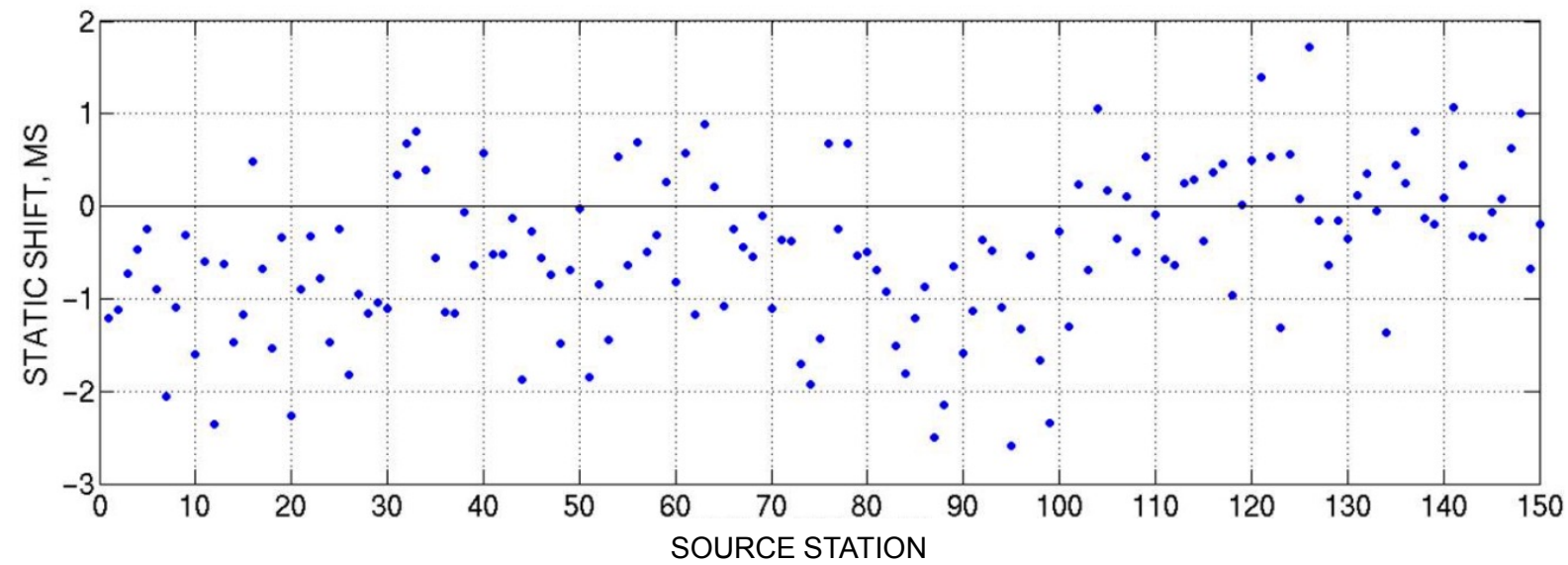

Figure 5. The plot of static shifts between corresponding sources. 

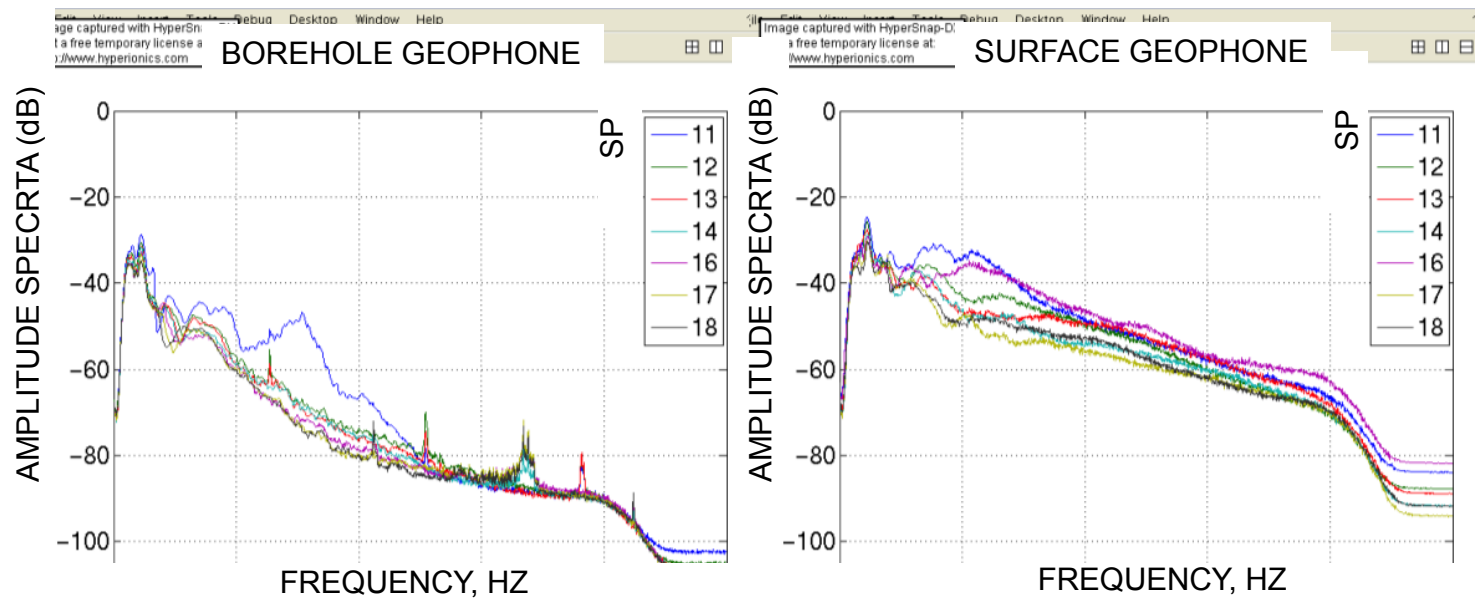

Figure 6. Comparison of the amplitude $(\mathrm{dB})$ spectra for borehole and surface geophones at several surface positions at pass 1 .

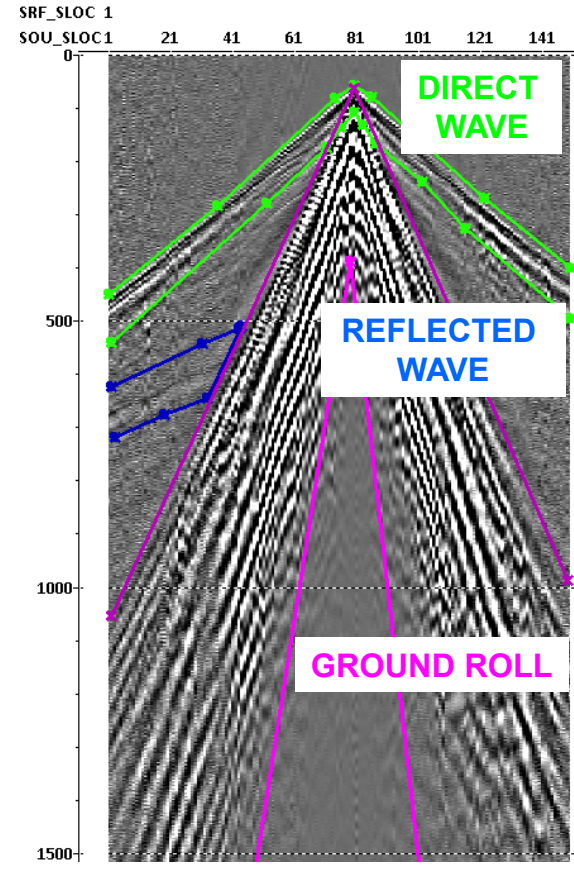

Figure 7. NRMS analysis: the gates for an average NRMS values calculations around direct (green), reflected (blue) and surface (pink) waves. 


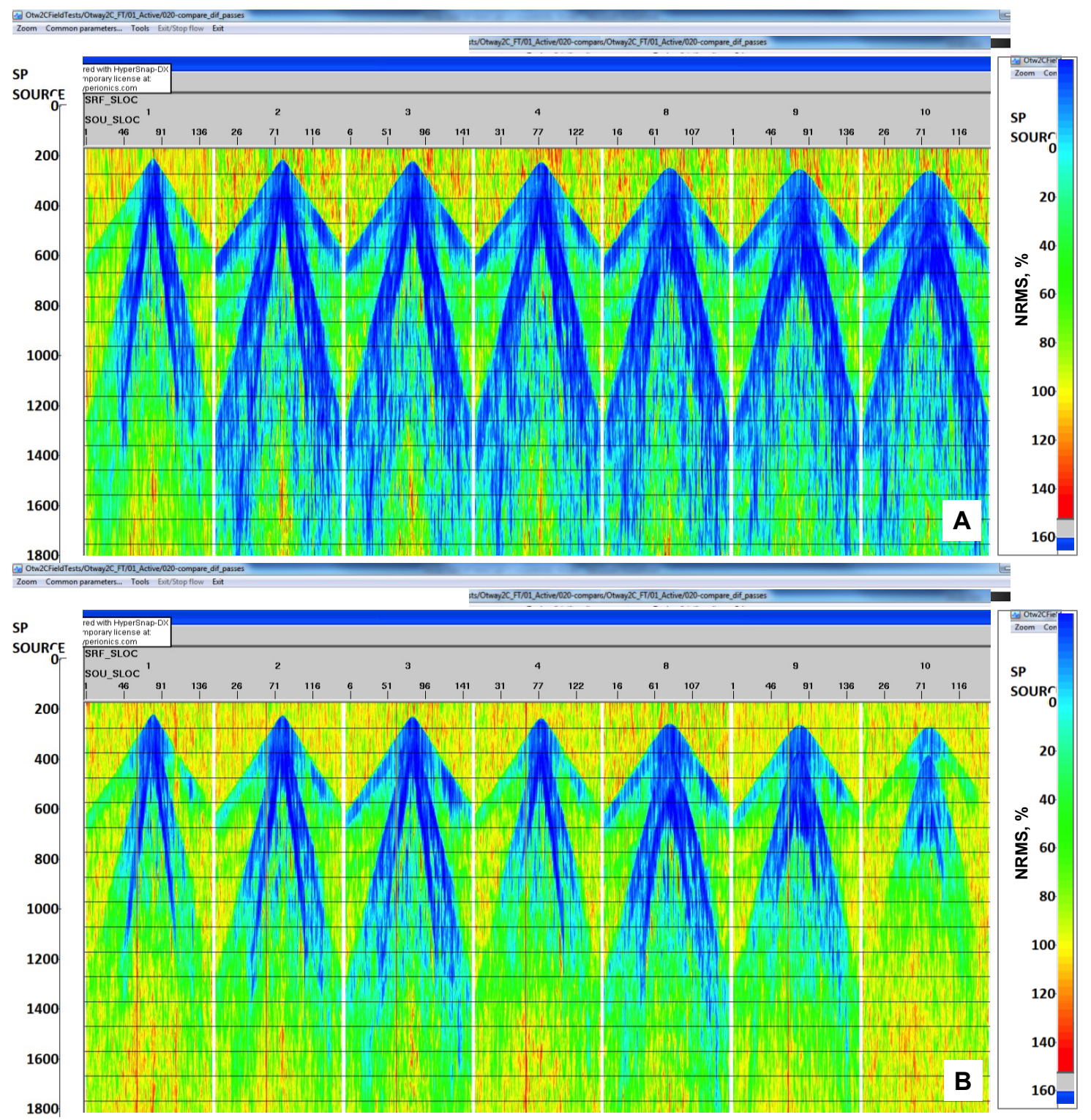

Figure 8. Comparison of NRMS values for borehole (A) and surface (B) geophones. 


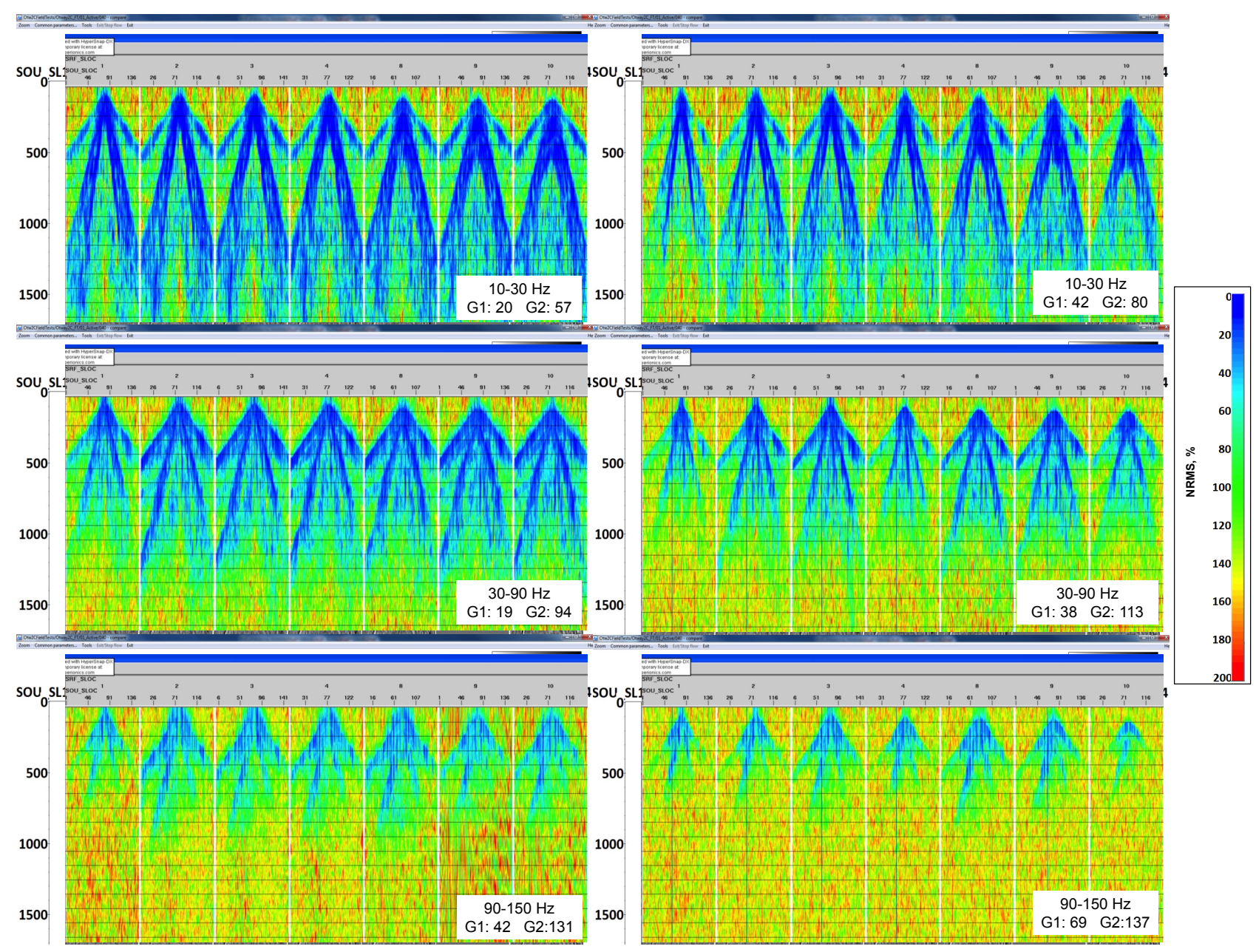

Figure 9. An example of NRMS values for borehole geophone data in three frequency ranges: 10-30 $\mathrm{Hz}$ (top), 30-90 Hz (middle) and 90-150 Hz (bottom). G1 and G2 values display NRMS estimations along direct wave arrival and ground roll respectively. 


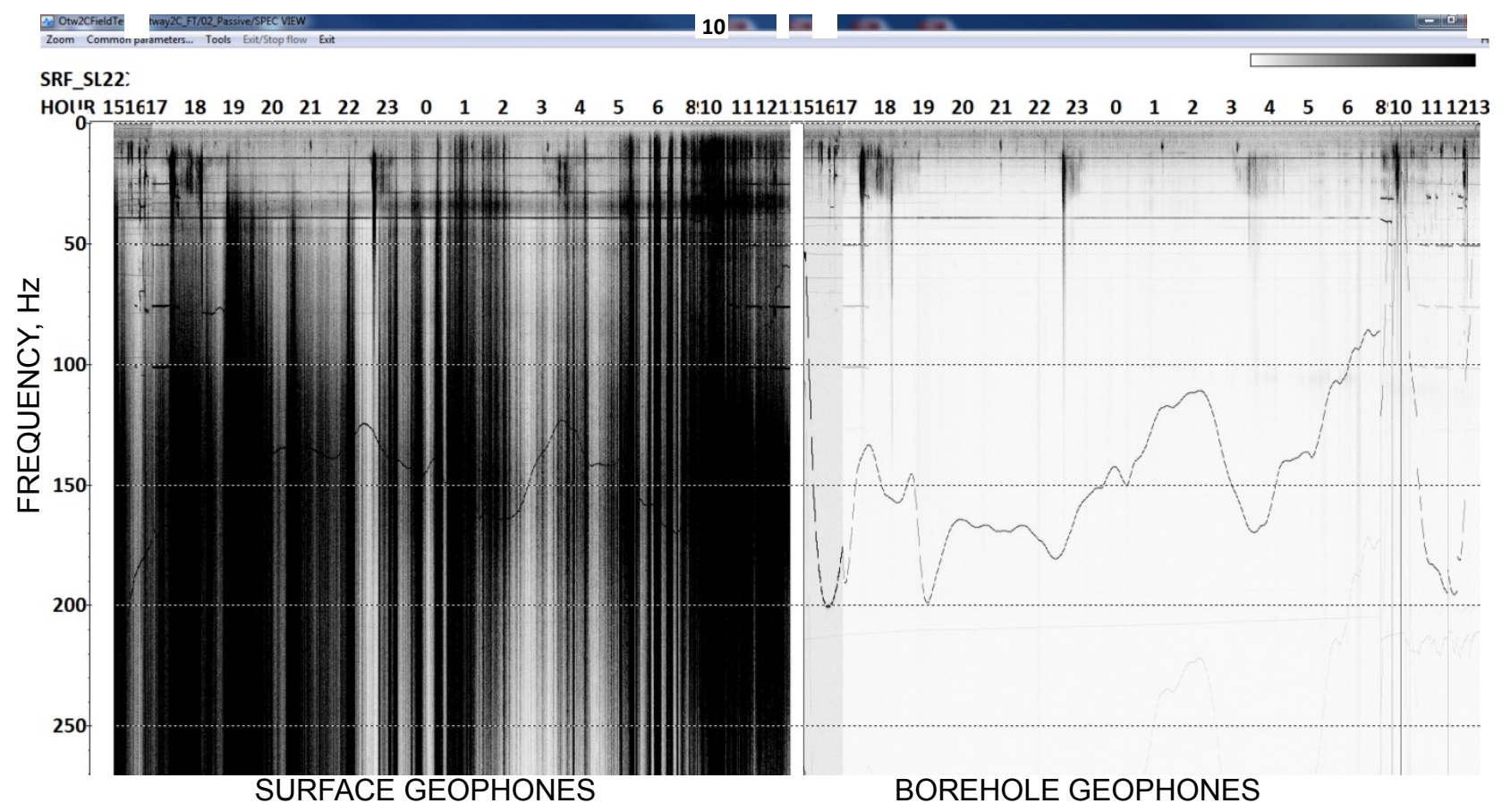

Figure 10. A spectrogram of the raw data acquired at SP 22 with surface (left) and borehole (right) geophones (horizontal axis is the acquisition time (in hours), vertical - frequency).

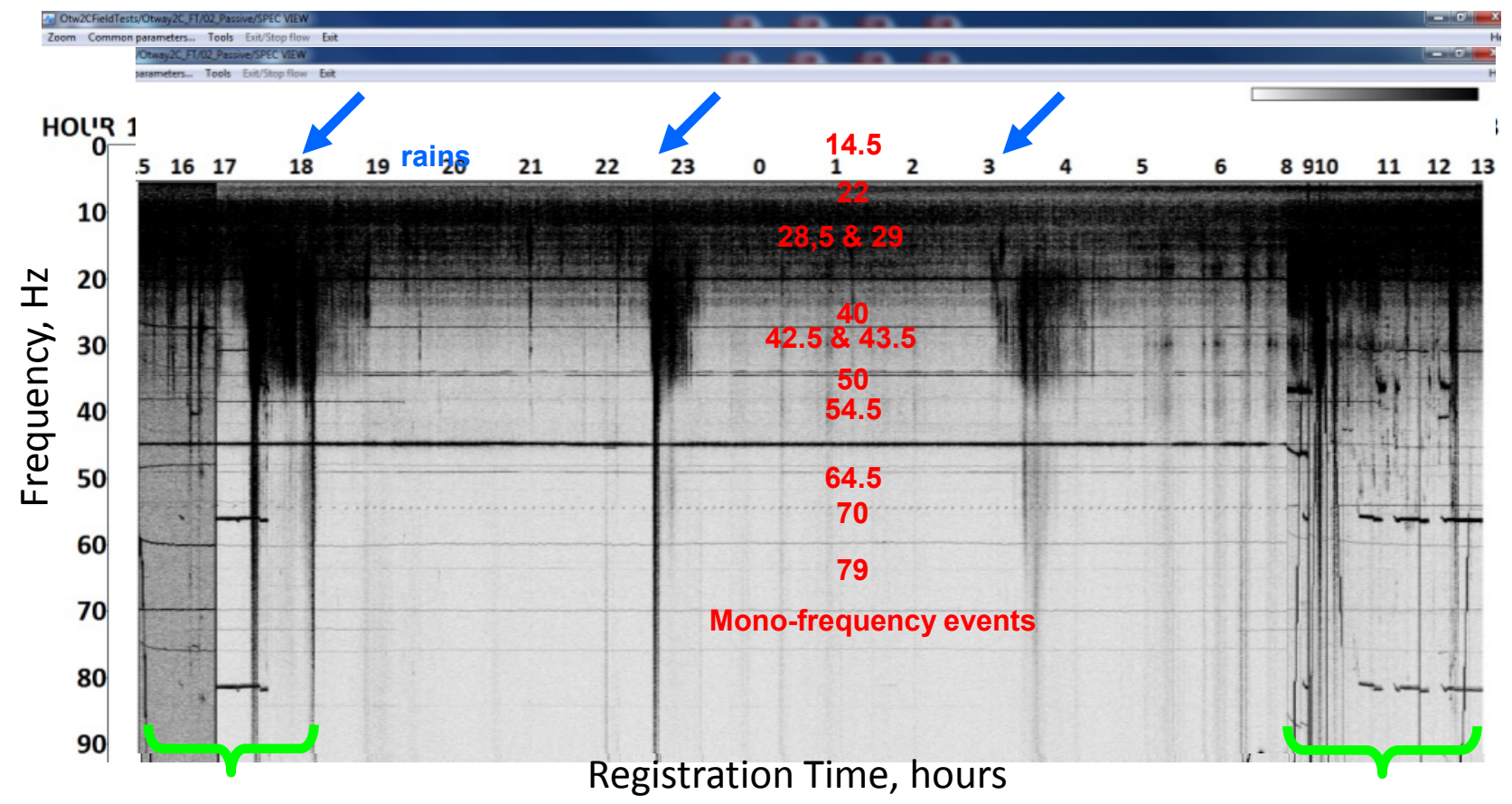

Figure 11. A fragment of the spectrogram of the raw data acquired at SP 22 with borehole geophones. 

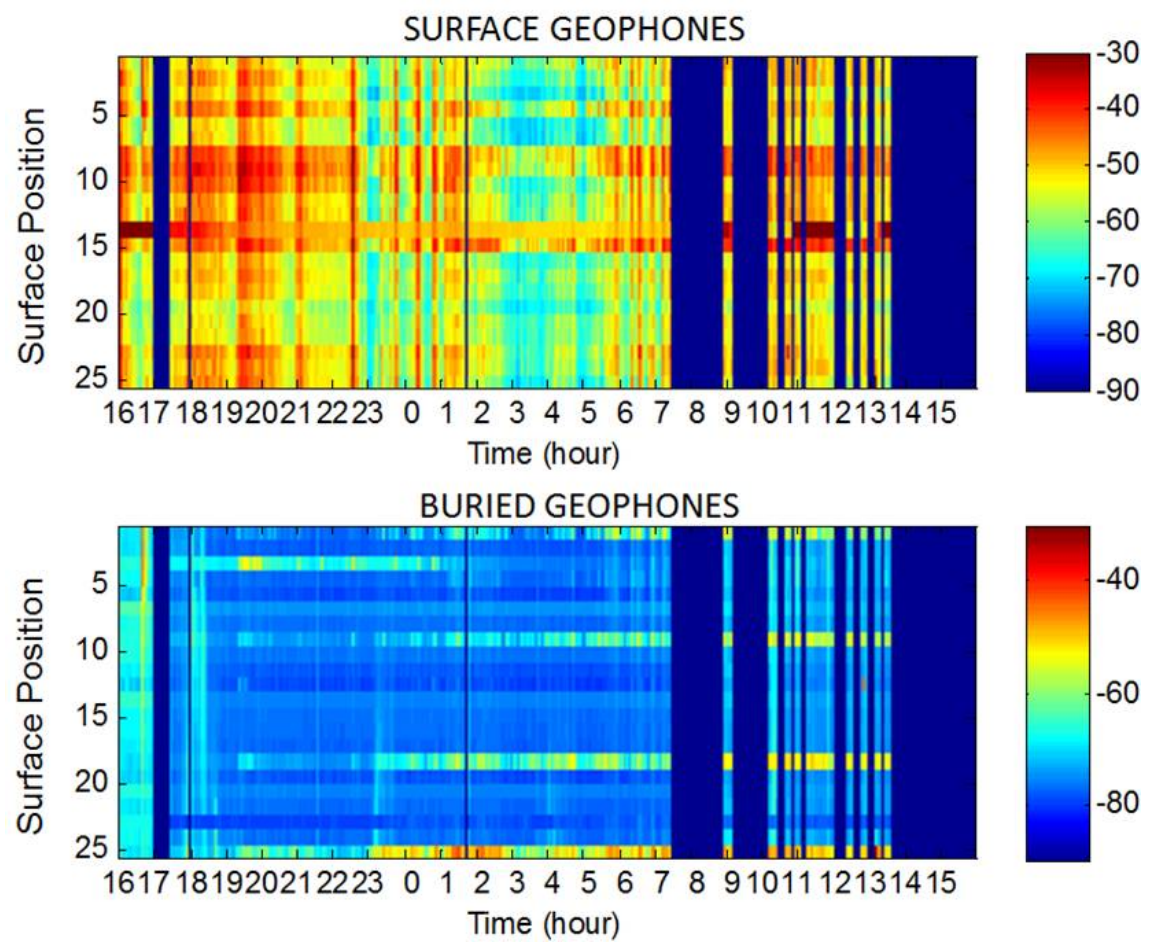

Figure 12. Average absolute amplitude on different geophones (in dB scale).

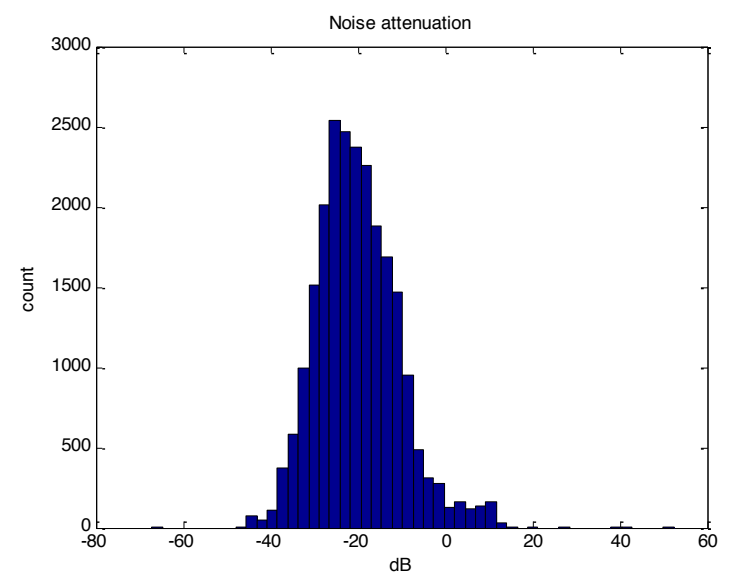

Figure 13. A histogram of noise attenuation. 


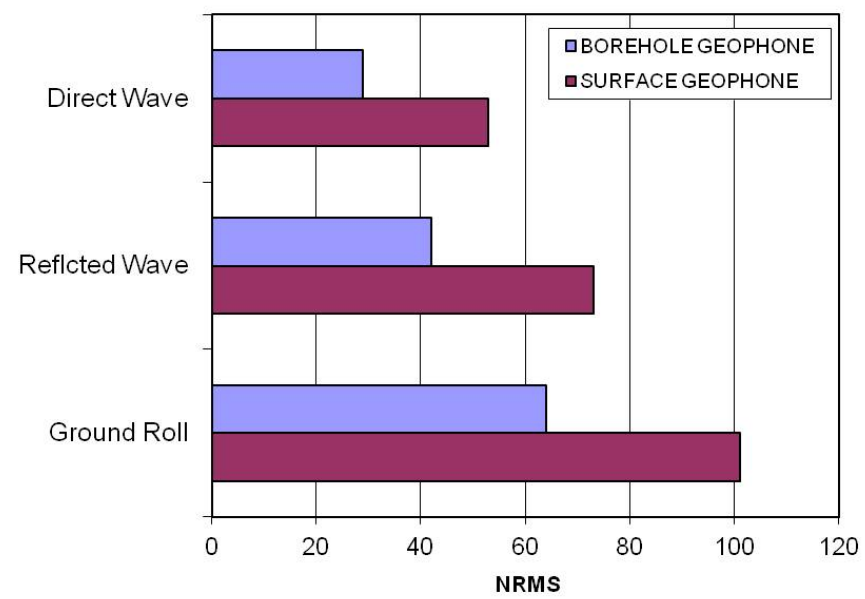

Figure 14. Average NRMS values for borehole (shown in blue) and surface (shown in purple) geophones for different seismic events: direct wave (top), reflected wave (middle) and ground roll (bottom).

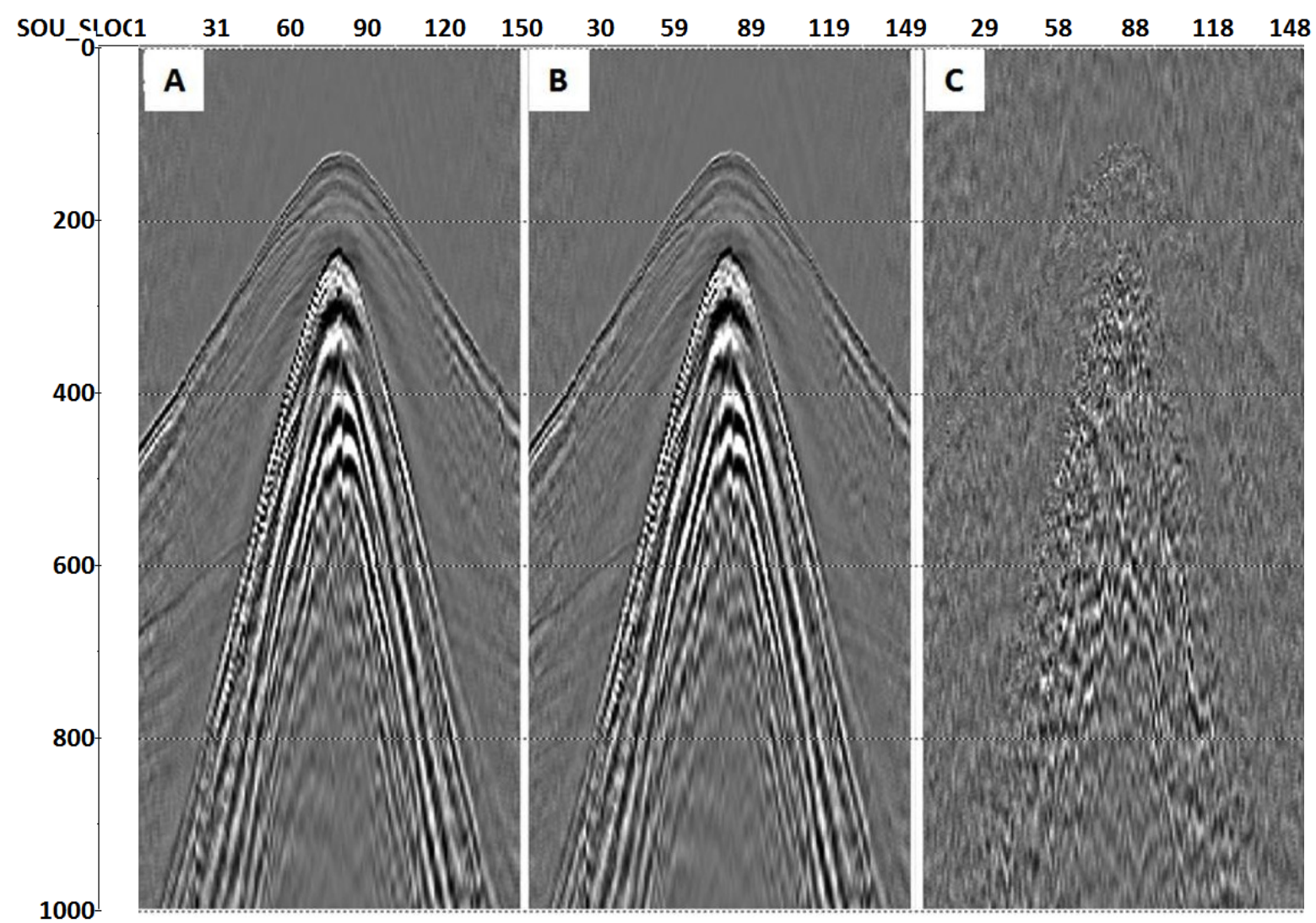

Figure 15. Two corresponding CRP seismograms (a-b) acquired during two different passes at SP 10 and the result of their subtraction (c). 

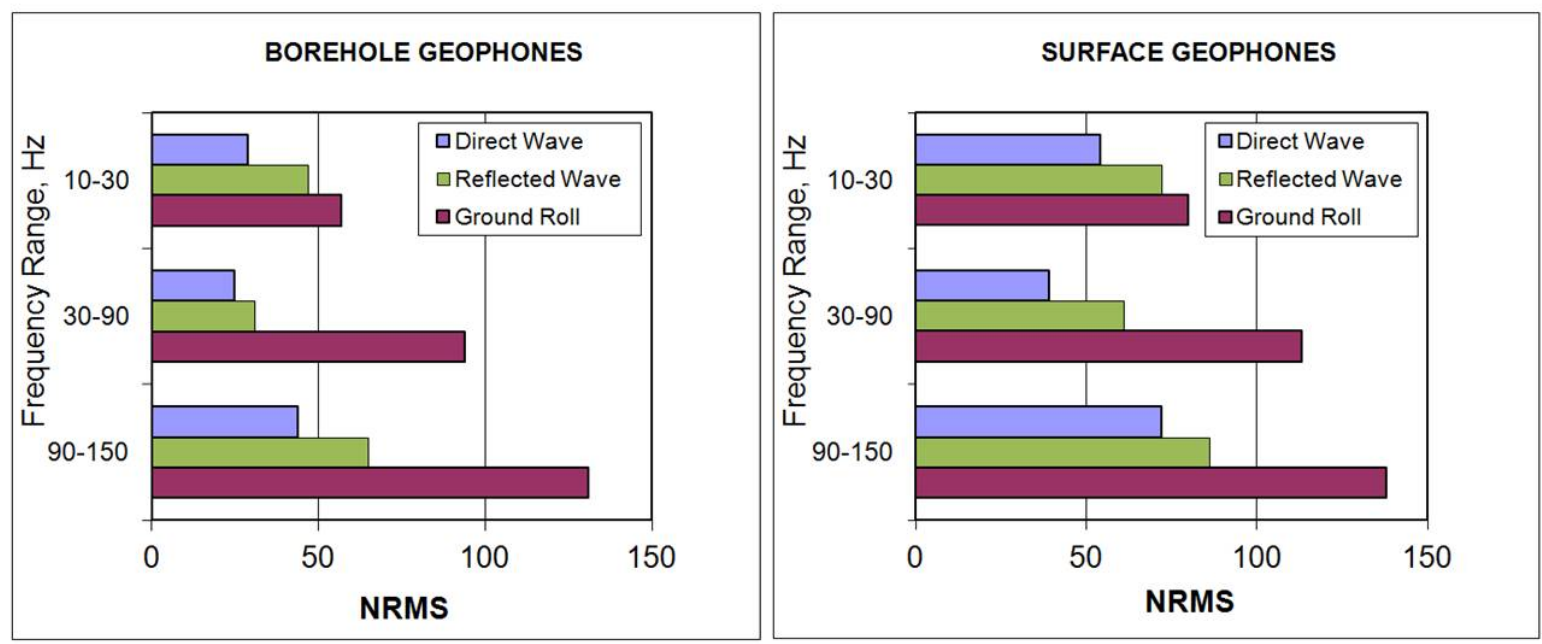

Figure 16. Average NRMS values (\%) for borehole and surface geophones for different frequency ranges estimated around direct, reflected and surface waves.

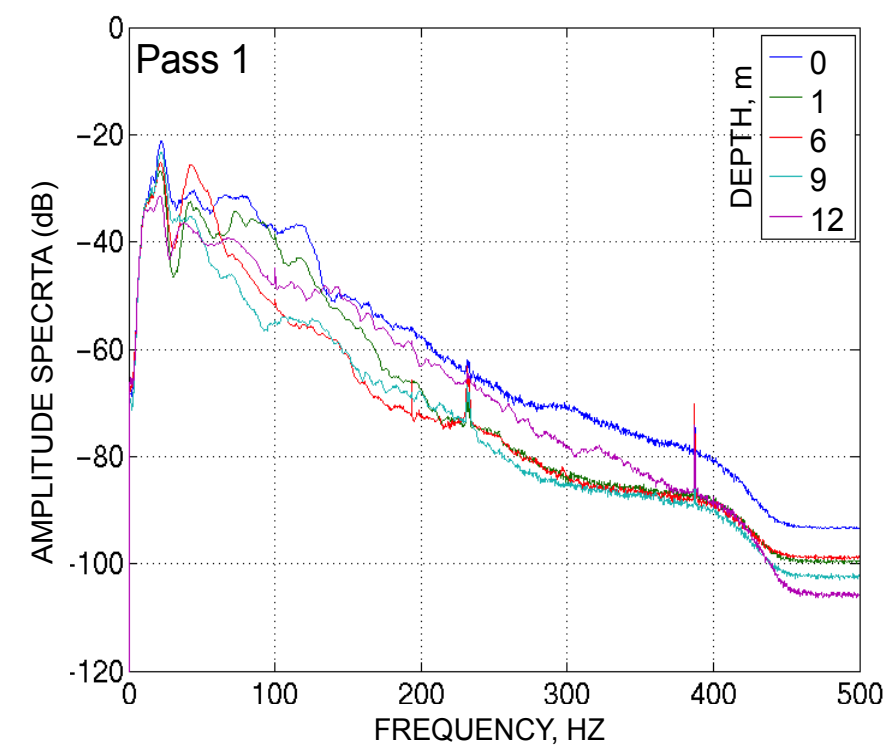

Figure 17. Comparison of the amplitude $(\mathrm{dB})$ spectra of the raw data at SP 6 for the first pass: one surface geophone and four geophones buried at depths of 1, 6, 9 and $12 \mathrm{~m}$. 


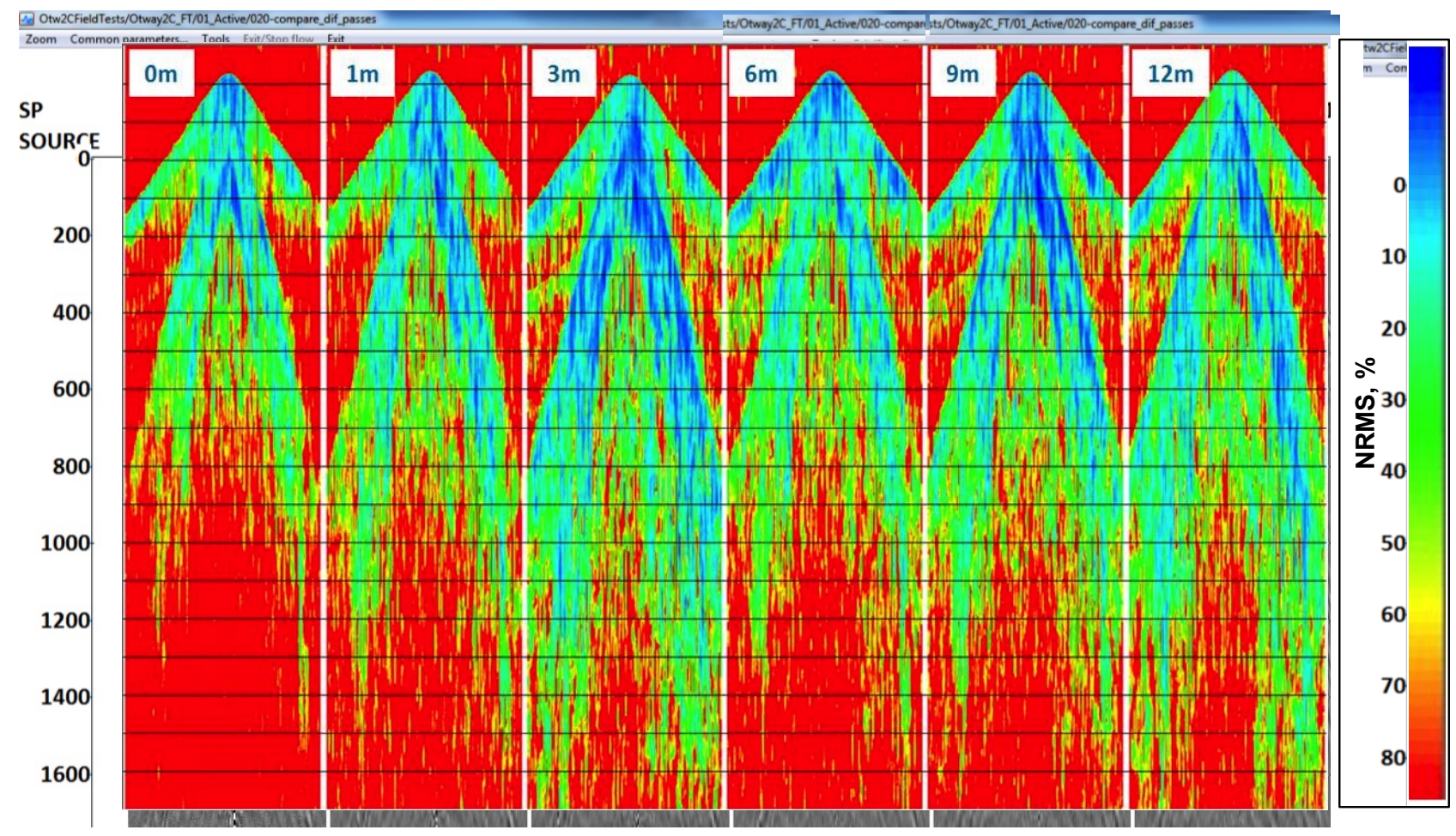

Figure 18. NRMS values of the raw data at SP 6 for two passes: one surface geophone and four geophones buried at depths of 1, 6, 9 and $12 \mathrm{~m}$. Numbers at the bottom of each figure show average NRMS values in the gates. DW - around direct wave, RW - reflected wave and GR - around surface wave. 